\title{
Nurses' Perspective of Patient Advocacy: A Systematic Mixed Studies
}

\section{Review}

Usama Saleh $^{1, *}$, Ahmad Aboshayga ${ }^{2}$, Tom O’Conner ${ }^{3}$, Moath Saleh ${ }^{4}$, Declan Patton ${ }^{5}$ and Ailyn May G. Ampang ${ }^{6}$

${ }^{1}$ Professor and Department Chair of Nursing, The Chicago School of Professional Psychology, Chicago, IL 60654, USA

${ }^{2}$ Chairperson, Saudi Board of Nursing, Saudi Council for Health Specialties Dean of School of Nursing, King Saud University, Riyadh, Saudi Arabia ${ }^{3}$ Deputy Head of Department, School of Nursing and Midwifery, Royal College of Surgeons Ireland, Dublin, Ireland

${ }^{4}$ Head of Training Organization and Regulation Department, King Abdullah Medical City, Makkah, Saudi Arabia

${ }^{5}$ Director and Senior Lecturer, School of Nursing and Midwifery, Royal College of Surgeons in Ireland, Dublin, Ireland

${ }^{6}$ Education Coordinator, Postgraduate Administration of Nursing and Allied Health Training, King Abdullah Medical City, Makkah, Saudi Arabia

\section{Abstract}

Aim: The aim of this review is to report on nurses' attitude and perception toward patient advocacy.

Design: Systematic reviews.

Data Source: We searched for evidence regarding nurses' attitude, perceptions, feelings, thoughts, or behaviors toward patient advocacy in three databases: CINHAL, MEDLINE, and OVID.

Review Methods: The inclusion criteria were studies on nurses' attitude, perception, feelings, thoughts, and behaviors toward patient advocacy published in academic journals in English language. Qualitative, quantitative, or mixed-method research studies were included. The Critical Appraisal Skills Program (CASP) as a quality assessment tool was used as a framework to review the quality of the full-text articles. Each article was awarded a value score out of 20

Results: A total of 21 studies were eligible, of the 998 studies retrieved from selected databases. The review resulted in two findings: (1) nurses consistently have positive attitude toward patient advocacy, and (2) the patient advocacy process includes four elements: (1) the client situation, (2) the nurse, (3) the advocacy interventions, and (4) the advocacy consequences.

Conclusion: Preparing professional nurses for the advocacy role is essential part of quality nursing care.

Impact: Patient advocacy is a complex concept and there has been inconsistencies on the use of this concept in the literature. Patient advocacy should be defined as a process with four elements: the patient situation, the nurse, the advocacy action, and the advocacy consequences. All nurses in different areas of nursing practice can utilize the findings of this study to improve patient care outcome.

\section{Publication History:}

Received: December 17, 2019

Accepted: January 07, 2020

Published: January 09, 2020

\section{Keywords:}

Systematic Review, MixedMethods, Patient Advocacy, Nursing Advocacy, Advocacy Actions, Advocacy Definition, Advocacy Attributes, Advocacy Types, Advocacy Theories

\section{Introduction}

Nursing advocacy is a very important function of nursing practice since it plays a critical role in keeping patients safe during their encounter with the healthcare system. Advocacy for patients is considered a fundamental value of professional nursing [1] and it is considered central to the nurse-patient relationship. The International Council for Nurses [2], and the American Nurses Association [3] include advocacy in their Codes of Ethics. The increasing awareness of patients about their rights places increasing demands both on the organization providing care and on the clinical and ethical competence of healthcare practitioners to respond to these demands. The nursing literatures usually identify nurses as the most appropriate professional group to advocate for patients. Although the concept of advocacy is frequently used in nursing research, the concept lacks maturity of the exact definition meaning to nursing researchers and practitioners [4]. The aim of this review is to report on nurses' attitude and perception toward patient advocacy.

\section{Background}

Nursing advocacy is a relatively modern concept. It was officially introduced to the profession on 1973 when the ICN Code of Ethics for Nurses reflected that nurses should advocate for their patients. Other Bodies of nursing included the advocacy concept into their Code of Ethics for Nurses [2]. For example, in 1976, the ANA announced the advocacy role in the Code of Ethics for Nurses. The code requested nurses to advocate for and protect the health and well-being of patients [3].
To fulfill the advocacy-nursing role, nurses need to understand the concept of advocacy by understanding its meaning, definitions and attributes. Several definitions of advocacy exist in the literature because it is defined in a variable way, depending on the context in which it is used.

\section{Meaning of advocacy}

Advocacy means ensuring those who are not always seen or heard have a voice to join other voices in decision-making and change process. The concept of advocacy originates from the Latin word 'advocatus', meaning one who is summoned to give evidence. The actions of advocacy are defined to verbally support argumentation for a cause. The action of advocacy is similar to the function of an advocate [5].

\section{Definitions of advocacy}

The concept of advocacy is defined in variable ways, depending on the context in which it is used. Traditionally, the concept of advocacy

"Corresponding Author: Prof. Usama Saleh, Professor and Department Chair of Nursing, The Chicago School of Professional Psychology, $325 \mathrm{~N}$ Wells St. Chicago, IL 60654, USA, Tel: 001-859-402-1616; E-mail: U_saleh@yahoo.com

Citation: Saleh U, Aboshayga A, O'Conner T, Saleh M, Patton D, et al (2020) Nurses' Perspective of Patient Advocacy: A Systematic Mixed Studies Review. Int J Nurs Clin Pract 7: 317. doi: https://doi.org/10.15344/2394-4978/2020/317

Copyright: (C) 2020 Saleh et al. This is an open-access article distributed under the terms of the Creative Commons Attribution License, which permits unrestricted use, distribution, and reproduction in any medium, provided the original author and source are credited. 
originates from the legal profession where a person's case is presented and defended [6,7]. Cole et al. [7] and Hamric [8] defined advocacy as an active support of clients in relation to their rights and choices. Nurses advocate for patients by clarifying healthcare decisions in support of patients' informed decision-making and protecting basic human rights such as autonomy. According to Sorensen and Ledema [9], there are three major definitions of the concept of nursing advocacy exist in the literature: (1) protection of patients against unwanted medical intervention, (2) the release of patients from discomfort of unnecessary treatment, and (3) empowering patients by making them aware of their rights. Malik and Rafferty [10] viewed advocacy from a triadic point that includes informing, advising, and counseling. The Word Health Organization [11] described advocacy as an action or a means of promoting well-being and patient's health status in all domains, including social, economic, political, behavioral, cultural, biological, and environmental contexts.

\section{Attributes of advocacy}

Thacker [12]identified the following defining attributes of advocacy based on extensive literature review: protecting the patient, listening to the patient's voice, moral and ethical decision making, and promoting patient well-being. Bu and Jezewski [13] developed a midrange theory of patient advocacy through concept analysis and identified three attributes of patient advocacy: safeguarding patients' autonomy, acting on behalf of patients, and championing social justice.

\section{Types of advocacy}

Kubsch, Sternard, Hovarter and Matzke [14] discussed five types of advocacy that were presented in the Kohlberg's theory of model stage development [15]: (1) legal advocacy is guarding the rights of patients to competent care, to reject care, informed consent, and privacy; (2) moral-ethical advocacy is upholding the patient's values in decision-making; (3) political advocacy is the facilitation of equal access to healthcare; (4) spiritual advocacy is providing access to spiritual support and reassurance; and (5) substitutive advocacy is the protection of interests of patients who are incapable of speaking for themselves. Megson [16] discussed six various types of advocacy identified by the British Institute for Learning Disabilities [17]. First, case advocacy focuses on one issue or set of issues. It usually has a short duration. Second, self-advocacy is where the person speaks up for herself or himself-if the person is able to do so. The third type of advocacy is 'peer advocacy.' It is when the advocate and the advocacy partner share similar experiences or environment. The 'paid independent advocacy' is the fourth type. Citizen advocacy, the fifth type, involve volunteers developing long-term relationships with people and speaking up for them. Finally, statutory advocacy is acting and making decision on behalf of individual who lack the mental capacity to do so for themselves.

\section{Active vs. Passive advocacy}

The literature made distinction between two types of advocacy: (1) active and (2) passive. Passive advocacy is where the nurse supports the patient's choices and decisions and take actions within the context of institutional policy. In active advocacy role, actions are undertaken on the client's, not the institution's behalf. The nurse's action of advocacy is based on professional standards and personal beliefs about what is morally and ethically right [18-20]. Segesten and Fagring [21] (1) a verbalized request from the patient; (2) a stated problem; and (3) stated that a patient advocacy situation can be triggered in three ways:

an independent decision by the nurse, particularly when the client is a child or very ill. Patient advocacy can be influenced by facilitators and barriers. One of the most important facilitators is the nurse-patient relationship [22]. In conclusion, the literature on the definition of nursing advocacy remain ambiguous, contested, and illusive.

\section{Aim}

This review aims to present the current state of evidence, undertaking a systematic review of literature in order to report on: What are nurses' attitudes and perceptions toward patient advocacy?

\section{Design}

The design of this study is a systematic review with mixed methods. The mixed studies review is a type of systematic review that synthesizes results from studies using quantitative and qualitative methods. We used mixed method systematic review to combine the strength of and compensate for the limitations of quantitative and qualitative methods. There were three reasons for using mixed method systematic review: (1) we need qualitative method to interpret quantitative results, (2) we need quantitative methods to generalize qualitative findings, and (3) we need both methods to capture a holistic view of the phenomenon [23].

\section{Search Methods}

A systematic literature searches of databases (Medline, CINHAL, and Ovid) was performed in February 2018 to identify articles written in English and published in academic journals regarding nurses' attitudes and perceptions toward patient advocacy. There was no restriction based on year or country of publication.

Inclusion criteria were studies that focused on nurses' attitudes, perceptions, thoughts, feelings, or behaviors toward patient advocacy. The review considered studies that included nurses in different areas of practice settings. The review excluded studies focused on neonatal/ pediatric nurses; however, the review included studies that neonatal/ pediatric nurses were part of the sample of the study. The review also

\begin{tabular}{|c|c|}
\hline \multicolumn{2}{|l|}{ Search Strategy } \\
\hline S1 & $\begin{array}{l}\text { Nurs* OR Health care worker OR } \\
\text { Health Care Provider OR Health } \\
\text { Care Professionals OR Health Care } \\
\text { Practitioner }\end{array}$ \\
\hline S2 & $\begin{array}{l}\text { Attitude OR Perception OR Opinion OR } \\
\text { Thoughts OR Feelings OR Behaviors }\end{array}$ \\
\hline S3 & $\begin{array}{l}\text { Advoca* OR Nursing Advocacy OR } \\
\text { Patient Advocacy OR Professional } \\
\text { Advocacy }\end{array}$ \\
\hline S4 & S1 and S2 \\
\hline S5 & $\mathrm{S} 3$ and $\mathrm{S} 4$ \\
\hline \multicolumn{2}{|l|}{ Search Results } \\
\hline CINAHL Data Base & 511 \\
\hline MEDLINE & 472 \\
\hline OVID & 4 \\
\hline Total retrieved articles & 987 \\
\hline
\end{tabular}

Int J Nurs Clin Pract

ISSN: $2394-4978$

IJNCP, an open access journal

Volume 7. 2020. 317 
Citation: Saleh U, Aboshayga A, O’Conner T, Saleh M, Patton D, et al (2020) Nurses' Perspective of Patient Advocacy: A Systematic Mixed Studies Review. Int J Nurs Clin Pract 7: 317. doi: https://doi.org/10.15344/2394-4978/2020/317

Page 3 of 8

considered studies excluded undergraduate and/or graduate nursing students but included interns/trainees. Quantitative, qualitative, or mixed methods approaches were included in the review. The review excluded studies published in non-English languages.

Following an initial review of key words in relevant literature, the search terms, strategies, and overall search process were defined. Table 1 illustrates a detailed search strategy and search results. We retrieved 987 articles from the three databases. Of these, 511 were from CINAHL, 472 from Medline, and 4 from OVID. Other sources of information used were gray literature and online resources, resulting in the inclusion of 11 articles.

Two researchers independently and blindly conducted the initial screening of titles and abstracts of articles identified through the search. In this step, we excluded 923 . We subsequently retained 75 , following a review based on the inclusion/exclusion criteria.

\section{Search Outcome}

A total of 75 articles were subjected to full-text review by the three researchers. Figure 1 illustrates the result of the search process. A total of 21 (6 CINHAL and 10 MEDLINE, and 5 other sources) articles remained after we removed duplicates and screened full-texts. The PRISMA flow diagram (figure 1) summarizes the phases of the search studies [24].

\section{Quality Appraisal}

The Critical Appraisal Skills Program (CASP) as a quality assessment tool, generated by the Center of Evidence-Based Medicine in the United Kingdom [25], was used as a framework to review the quality of the full-text articles. Articles were assessed by two independent reviewers for methodological validity. Any disagreement that arose between the reviewers were resolved through discussion or with a third reviewer. The CASP Relevant questions were applied to the individual studies (Table 2 and Table 3). The 10 criteria of the CASP appraisal tool are listed in table 2 and table 3 . The article was assessed against each CASP criterion. A value of zero was giving if the article contained no information, a value of 1 if the article included a moderate amount of information and a score of 2 if the article fully addressed the criterion. Each article was awarded a value score out of 20 to signify its adherence to the CASP criteria.

\section{Data Abstraction}

Data were extracted from papers included in the review using a standardized data extraction tool as illustrated in table 4 and table 5 (supplementary file). The extracted data included the author's name, country of publication, aim of the study, methodology/design, sample, data collection method, key findings, and recommendations. A quality appraised (CASP) score of each article that resulted from the appraisal process was also included in the data extraction form.

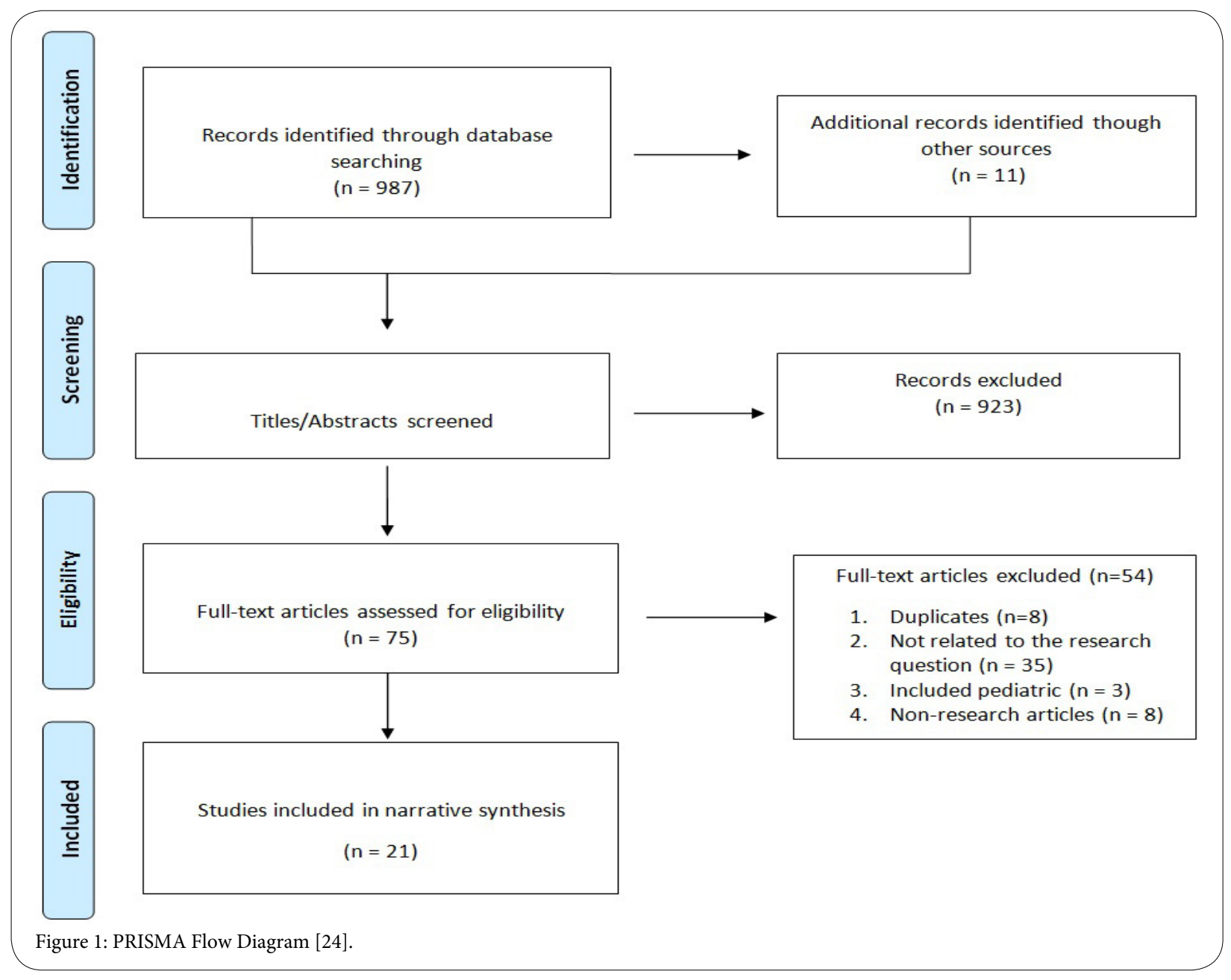


Citation: Saleh U, Aboshayga A, O’Conner T, Saleh M, Patton D, et al (2020) Nurses' Perspective of Patient Advocacy: A Systematic Mixed Studies Review. Int J Nurs Clin Pract 7: 317. doi: https://doi.org/10.15344/2394-4978/2020/317
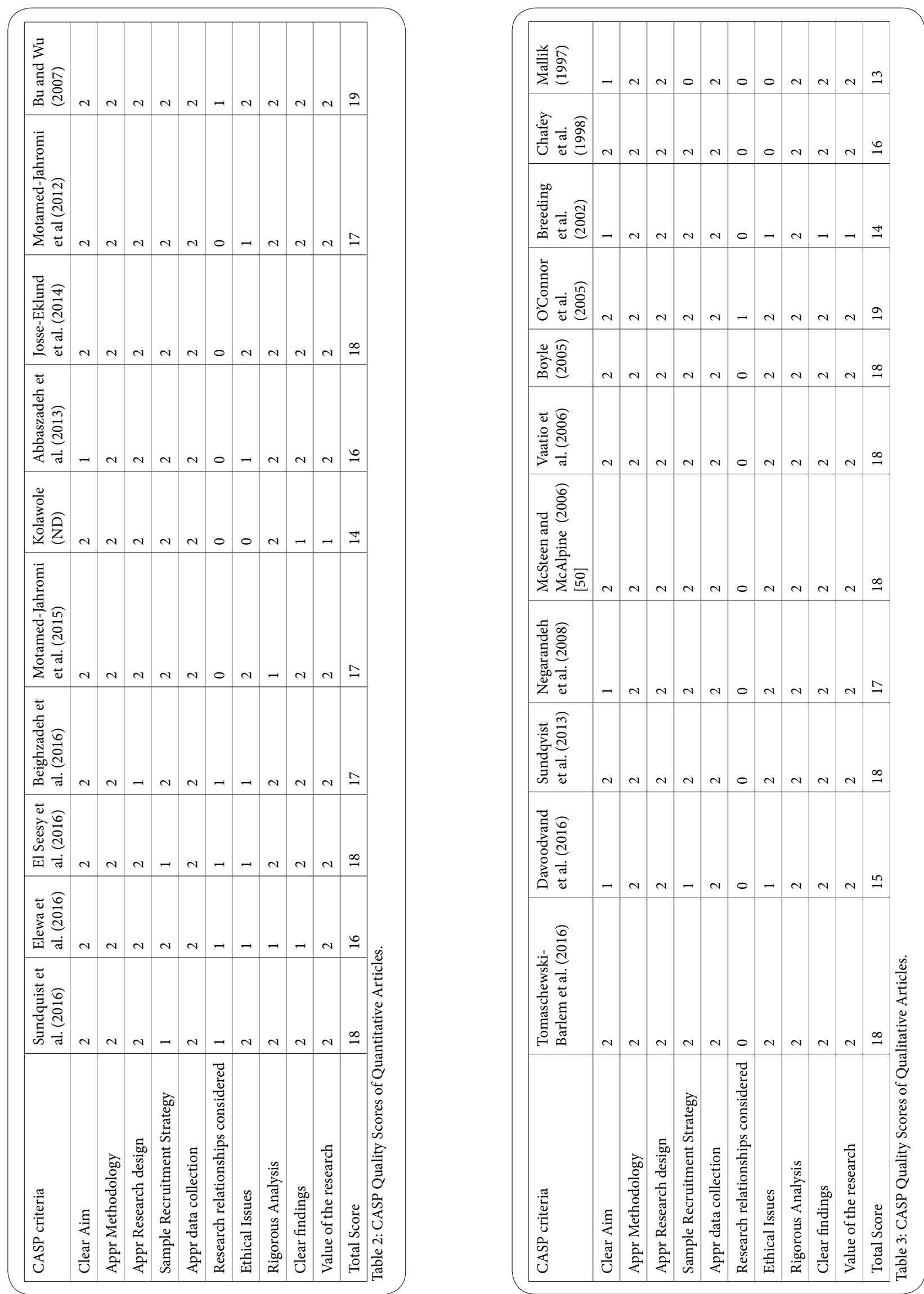


\section{Synthesis}

Searches identified 998 studies. During the initial screening step, titles and abstracts were screened and resulted in excluding 923 papers. Of the remaining 75 papers, 8 studies were excluded due to duplication and 46 papers were excluded because they did not meet the inclusion criteria. Twenty-one (21) papers were eventually included for the review. The PRISMA flow diagram summarizes the included studies based on the eligibility criteria (figure 1).

\section{Results}

The 21 studies that addressed the aim of the systematic review are contained in table 4 and table 5. Most of the selected studies were conducted in Iran $(n=6)$, USA $(n=4)$, and Sweden $(n=3)$. The remaining studies were conducted in Saudi Arabia $(\mathrm{n}=1)$, Egypt $(\mathrm{n}=$ $1)$, Brazil $(n=1)$, Nigeria $(n=1)$, Finland $(n=1)$, Ireland $(n=1)$, United Kingdom $(n=1)$ and Australia $(n=1)$.

Eleven ( $\mathrm{n}=11)$ of the studies used a qualitative methodology (Table $5)$ and the rest $(n=10)$ of the studies used a quantitative methodological approach (Table 4) (supplementary file). Cross-sectional design was the dominant design used in quantitative studies. Phenomenology $(n=4)$, grounded theory $(n=1)$, focus group $(n=2)$, exploratory/ descriptive $(n=4)$. Surveys $(n=10)$ was the only data collection method used in quantitative studies while interviews $(n=11)$ was the data collection method used in qualitative studies.

The studies used nurses from different areas of clinical nursing practice. Nurses from the following clinical specialties were included in the studies: medical-surgical nurses, general ward nurses, nurse anesthetists, oncology nurses, critical care (ICU, CCU, ED) nurses, maternity, mental health, community health, elderly care nurses, hospice nurses, perioperative nurses, ophthalmology muses. Two studies [26,27] included a sample of nurses and patients to better capture the experience of patient advocacy. Kolawole (ND) [26] used 219 nurses in addition to 25 patients; meanwhile Vaartio et al. [27] used a sample of 21 nurses and 22 patients.

Two of the studies $[28,29]$ were conducted on phases to develop advocacy instruments. Sundqvist et al. [28] used three phases to translate and adapt the Protective Nursing Advocacy Scale (PNAS) into a Swedish version. Translation on the PNAS items took place in phase I. Phase II included psychometric evaluation on the newly translated PNAS instrument. The final phase (Phase III) was a description of Swedish RNAs of advocacy beliefs. Bu and Wu [29] study consisted of two phases to develop an instrument to measure nurses' attitude toward patient advocacy. The first phase consisted of two stages of psychometric evaluation (1) defining the construct, and (2) generating the items. The second phase of the study was to examine reliability and validity of the instrument.

The included studies were subjected to appraisal under the Critical Appraisal Skills Program [25]. Table 2 and table 3 illustrate the criteria and the results of the appraisal. Each article was awarded a value score out of 20 to signify its adherence to the criteria. The total appraisal points of the articles ranged from 13-19 out of $20(\mathrm{~m}=16.9$, $\mathrm{SD}=1.7)$. Fourteen studies $(\mathrm{n}=14,66 \%)$ score 17 and above. A total of seven $(n=7,33 \%)$ studies scored between 13-16, indicating gaps and limitations in relation to aims, data collection methods, research relationship, and ethical issues. None of the studies scored less than 13 and all studies were considered suitable for the systematic review as they addressed and met the inclusion criteria.
Ten quantitative studies used different instruments to measure nurses' attitude toward patient advocacy. All of these studies consistently reported that nurses, in many different specialties, have positive attitude toward patient advocacy [22,26,28-35]. In Abbaszadeh et al. [34] study, nurses reported they should provide protective nursing advocacy for their patients while Nurse interns believe that patents should be provided interpreter when needed as part of advocacy [36].

The studies used different specialty nursing population such as oncology nurses [29,31], nurse anesthetists [28], nurse interns [30], critical care nurses [32], ER general nurses, and mental health nurses [33], surgical nurses [26], critical care, general, and mental health nurses [34]. Community health nurses caring for elderly [22], critical care, general ward, and mental health nurses [35].

The reviewed studies suggested that advocacy is viewed by nurses as a process that consists of four elements: (1) the client situation, (2) the nurse, (3) the advocacy actions, and (4) the consequences of advocacy.

The patient situation has been described in the reviewed studies as morally inappropriate situation [36], ethically difficult situation [37], a complex confrontation of significant ethical and moral dilemmas [38], patient vulnerability [39] or conflict/potential conflict situation, patient's fear, and threat to the patient's human rights [40].

The characteristics of the nurse is important for the advocacy role. The reviewed studies described the advocate nurse as autonomous [36], professional [27] morally obligated [39], values individuality [27], and knowledgeable with legitimate expertise [40].

The reviewed studies have listed advocacy actions delivered by the nurses. Several of these actions are within the nurse-patient relationship $[20,38,40]$ and within open dialogue with the patients [36]. Protecting the patients [37,40-43] is one of the recurrent theme of the advocacy action. Protecting patients means: (1) taking care of patients; (2) prioritizing patient health, (3) defending patients' rights, (4) commitment of the completion of the care period [36,37], representing the patient [42]. Table 6 lists actions of advocacy described in the reviewed studies. Finally, in the advocacy process, nurses respond to unethical patient situations to prevent incompetent or inappropriate practice [40] to achieve the best possible health outcomes $[36,37,40]$.

In conclusion, the findings of the reviewed studies suggest there is an advocacy process model. The process is triggered by a morally or ethically inappropriate patient situation that mandates a professional nurse to respond with an advocacy action, ending the process with more favorable patient's health outcome.

\section{Discussion}

This comprehensive systematic review identified 21 studies that investigated nurses' attitude and perception toward patient advocacy. It is clear that nursing advocacy is a complex concept that has ethical and clinical importance to healthcare. The findings of this systematic review showed inconsistencies in the definitions of nursing advocacy. This finding is consistent with other published studies [6,7]. Cole et. al. [7] and Hamric [8] defined advocacy as an active support of clients in relation to their rights and choices. Sorensen and Ledema [9] reported three major definitions of advocacy: (1) protection of patients against unwanted medical intervention, (2) the release of patients from 
Citation: Saleh U, Aboshayga A, O’Conner T, Saleh M, Patton D, et al (2020) Nurses' Perspective of Patient Advocacy: A Systematic Mixed Studies Review. Int J Nurs Clin Pract 7: 317. doi: https://doi.org/10.15344/2394-4978/2020/317

Page 6 of 8

discomfort of unnecessary treatment, and (3) empowering patients by making them aware of their rights. Malik and Rafferty [10] viewed advocacy as informing, advising, and counseling. In conclusion, the literature on the definition of nursing advocacy remain ambiguous, contested, and illusive. The literature reflects an ill-defined concept of advocacy. The variance in defining this concept may be due to the fact that the concept of advocacy is used in a number of different disciplines. In addition, this variance in definition may be the result of attempts to define an abstract concept that reflects differing fundamental values and philosophical issues.
There were consistent reporting that nurses, in different specialties, have positive attitude toward patient advocacy [22,26,28-35]. This finding support previous studies' findings [44-47]. This finding explains nurses' commitment to patient advocacy and very responsive to the International Council of Nursing (ICN) and the American Nurses Association (ANA) Codes of Ethics.

Another key finding of this systematic review suggests that advocacy is a process that is triggered by a morally or ethically inappropriate patient situation that mandates a nurse to respond with

\begin{tabular}{|c|c|}
\hline Author(s) (year) & Advocacy Actions \\
\hline $\begin{array}{l}\text { El Seesy and Al } \\
\text { Nagshabani }(2016)\end{array}$ & Acting on behalf of patients \\
\hline $\begin{array}{l}\text { Tomaschewski- } \\
\text { Barlem et al. (2016) }\end{array}$ & $\begin{array}{l}\text { Open dialogue with patients } \\
\text { Courage to tell the truth } \\
\text { Resisting barriers }\end{array}$ \\
\hline $\begin{array}{l}\text { Davoodvand, } \\
\text { Abbaszadeh and } \\
\text { Ahmadi (2016) }\end{array}$ & $\begin{array}{l}\text { Protecting the patient } \\
\text { Taking care of patients } \\
\text { Prioritizing patient health } \\
\text { Defending patients' rights } \\
\text { Commitment of the completion of the care period }\end{array}$ \\
\hline $\begin{array}{l}\text { Sundqvist and } \\
\text { Carlsson (2014) }\end{array}$ & $\begin{array}{l}\text { Providing safe care } \\
\text { Safeguarding the patient from harm } \\
\text { Informing the patient } \\
\text { Providing dignified care } \\
\text { Treating patient respectfully } \\
\text { Establishing trust } \\
\text { Defending patients' rights } \\
\text { Providing vicarious autonomy }\end{array}$ \\
\hline $\begin{array}{l}\text { Negarandeh, } \\
\text { Oskouie, Ahmadi and } \\
\text { Nikravesh (2008) }\end{array}$ & $\begin{array}{l}\text { Informing and educating } \\
\text { Valuing and respecting } \\
\text { Supporting physically, emotionally, and financially } \\
\text { Protecting and representing } \\
\text { Promoting continuity of care }\end{array}$ \\
\hline $\mathrm{Bu}$ and $\mathrm{Wu}(2007)$ & $\begin{array}{l}\text { Safeguarding patients' autonomy } \\
\text { Acting on behalf of the patients } \\
\text { Championing social justice } \\
\text { Representing the nurses' patient advocacy role at the microsocial level } \\
\text { Representing nurse's patient advocacy role at the macrosocial level }\end{array}$ \\
\hline $\begin{array}{l}\text { Mcsteen and } \\
\text { McAlpine (2006) }\end{array}$ & $\begin{array}{l}\text { Acting as a guide during transition at the end of life } \\
\text { Acting as a liaison between the healthcare team and family } \\
\text { Acting to support the meaning of the illness to the patient and family }\end{array}$ \\
\hline $\begin{array}{l}\text { Vaartio, Leino- } \\
\text { Kilpi, Salanterä and } \\
\text { Suominen (2006) }\end{array}$ & $\begin{array}{l}\text { Integrate aspects of individuality } \\
\text { Integrate experience of empowering } \\
\text { Providing exceptional care } \\
\text { Provide continuum care } \\
\text { Using a process of analyzing, counseling, responding, shielding, and whistleblowing activities in clinical nursing practice }\end{array}$ \\
\hline Boyle (2005) & $\begin{array}{l}\text { Giving voice protecting patients from harm } \\
\text { Making sure that patients are cared for and safe } \\
\text { Informing patients and their family members about their rights } \\
\text { Providing facts about their healthcare acting on behalf of the patient by helping, intervening, and assisting the patient to } \\
\text { best outcome }\end{array}$ \\
\hline $\begin{array}{l}\text { O'Connor and Kelly } \\
(2005)\end{array}$ & $\begin{array}{l}\text { Clinical advocacy } \\
\text { Organizational advocacy }\end{array}$ \\
\hline $\begin{array}{l}\text { Chafey, Rhea, } \\
\text { Shannon and Spencer } \\
\text { (1998) }\end{array}$ & $\begin{array}{l}\text { Action within the nurse-patient relationship } \\
\text { Coordination with the system } \\
\text { Intervening with the system on the client's behalf } \\
\text { Empowering the client }\end{array}$ \\
\hline Mallik (1997) & $\begin{array}{l}\text { Use direct and indirect means to protect } \\
\text { Represent family/patient choice }\end{array}$ \\
\hline
\end{tabular}


Citation: Saleh U, Aboshayga A, O’Conner T, Saleh M, Patton D, et al (2020) Nurses' Perspective of Patient Advocacy: A Systematic Mixed Studies Review. Int J Nurs Clin Pract 7: 317. doi: https://doi.org/10.15344/2394-4978/2020/317

an advocacy action, ending the process with more favorable patient's health outcome. This finding led us to think of advocacy in more conceptually that yielded the advocacy process model that consists of four elements: the patient, the nurse, the advocacy response, and the advocacy consequences. Viewing advocacy as a process is consistent with Bu and Jezewski [13] Theory of Patient Advocacy. According to $\mathrm{Bu}$ and Jezewski theory [13], patient advocacy is viewed as a processor or strategy with a set of actions to support and maintain and safeguard patients 'rights, best interests and values in the healthcare system. This process can be influenced by facilitating and obstructing factors, at an individual and at an organizational level.

The findings of this review have revealed a wide range of advocacy actions that can be undertaken by nurses (Table 6). These actions can be as simple as opening dialogue with the patients and providing dignified care to acting on behalf of the patient by helping, intervening, and assisting the patient to best health outcome. Advocacy actions are delivered at different levels: patient level, institutional level or community level. This finding is consistent with previous advocacy models such as the Functional Model of Patient Advocacy [48], the Social Advocacy Theory [49], the Theory of Patient Advocacy [13], and the Sphere of Nursing Advocacy (SNA) model [1]. The Functional Model of Patient Advocacy focuses on informing patients about their disease processes, treatments, medications, and procedures, and placing the responsibilities of decision making where it belongs, in the patients' hands. According to this model, advocacy involves informing-supplying patients with information needed to make informed choices-patients and then supporting the decision they make [48]. The Social Advocacy Theory calls nurses to not only advocate for patients at the bedside, but also advocate for change within and across institutions, communities, and societies [49]. Bu and Jezewski [13] stated that the patient advocacy includes three broad core attributes: safeguarding patients' autonomy, acting on behalf of patients, and championing social justice. The first two core attributes take place at a microsocial level and the third at the macrosocial level. The SNA model [1] provides a protective shield for the clients who are unable to self-advocate. The client and the nurse can be simultaneously acting as advocates on the client's behalf--the client is practicing self-advocacy through the pores; and the nurse advocate for clients through the protective spheres.

\section{Conclusion}

The patient Advocacy Process Model is a source of influence and inspiration in refining and validating the nursing advocacy concept. The Advocacy Process Model can guide research which result in information or data that add to the accumulated advocacy knowledge. Researchers need to use the theories of advocacy to guide the research process, forms the research questions, aids in design, and analysis and interpretation. In terms of practice, if theory is expected to benefit practice, it must be developed co-operatively with people who practice nursing. Advocacy theory should provide the principles that underpin practice and help to generate further nursing knowledge. However, a lack of agreement in the professional literature on nursing advocacy theory confuses nurses and causes many to dismiss nursing theory as irrelevant to practice.

The main strength of this review were the systematic approach and reproducible method. It was based on explicit search strategies. The review used three databases and used mixed studies review that included studies with diverse designs and addressed complex review question. The mixed studies reviews combined the strength of both quantitative and qualitative studies. The review team included five experienced researchers and one coordinator. The research team have extensive and diverse research experience.

As in any review, one primary concern is that so called grey literature. The depth of critical appraisal of the research articles was limited by the skills and ability of the researchers. In addition, publication bias may have occurred. Positive results are more likely to be submitted and published in scientific journals than negative results. Finally, the search was limited to three databases mainly in health; thus not all articles were identified in this review.

The twenty-one reviewed articles were all written in English but not from English speaking countries. The studies were published from different parts of the globe with different cultural beliefs. Advocacy can be influenced by different religious, cultural, beliefs, and traditional practices. These factors can be influential of the generalizability and the transferability of the findings.

\section{Author's Contribution}

Usama Saleh: PI, searching, screening, critiquing, data abstraction, evaluating, synthesis, discussion, conclusion, coordinating, writing, and overall supervision.

Ahmad Aboshayga: Searching, screening, evaluating, critiquing, data abstraction, synthesis, discussion, writing, reviewing.

Tom O'Conner: Searching, screening, writing, synthesis, discussion, and reviewing.

Moath Saleh: Searching, data abstraction, synthesis, writing, and reviewing.

Declan Patton: Searching, writing, and reviewing.

Ailyn May G. Ampang: Clerical and administrative support.

\section{Competing Interests}

The authors declare that they have no competing interests.

\section{References}

1. Hanks RG (2006) Sphere of nursing advocacy model. Nurs Forum 40: 75-78.

2. International Council of Nurses (2012) Code of Ethics for Nurses. ICN Geneva, Switzerland.

3. American Nurses Association (2015) Code of Ethics for Nurse with Interpretive Statements: ANA. Maryland: Silver Spring.

4. Vaartio $H$, Leino-Kilpi $H$, Suominen T, Puukka $P$ (2009) Measuring Nursing Advocacy in Procedural Pain Care-development and validation of an instrument. Pain Manag Nurs 10: 206-219.

5. Vaartio H, Leino-Kilpi $\mathrm{H}$ (2005) Nursing advocacy: A review of the empirical research 1990-2003. Int J Nurs Stud 42: 705-714.

6. Spence K (2011) Ethical advocacy based on caring: a model for neonata and pediatric nurses. J Ped Child HIth 47: 642-645.

7. Cole C, Wellard S, Mummery J (2014) Problematizing autonomy and advocacy in nursing. Nursing Ethics 21: 576-582.

8. Hamric AB (2000) What is happening to advocacy? Nursing Outlook 48 103-104.

9. Sorensen R, Ledema R (2007) Advocacy at end-of-life. Research design: An ethnographic study of an ICU. Int J Nurs Stud 44: 1343-1353.

10. Malik M, Rafferty AM (2000) Diffusion of the concept of advocacy. J Nurs Scholarsh 32: 399-404.

11. World Health Organization (2018) Workplace health promotion. 
Citation: Saleh U, Aboshayga A, O’Conner T, Saleh M, Patton D, et al (2020) Nurses' Perspective of Patient Advocacy: A Systematic Mixed Studies Review. Int J Nurs Clin Pract 7: 317. doi: https://doi.org/10.15344/2394-4978/2020/317

Page 8 of 8

12. Thacker K (2008) Nurses' advocacy behaviors in end-of-life nursing care Nurs Ethics 5: 174-185.

13. Bu X Jezewski MA (2006) Developing a mid-range theory of patient advocacy through concept analysis. J Adv Nurs 57: 101-110.

14. Kubsch SM, Sternard J, Hovarter R, Matzke V (2004) A holistic model of advocacy: Factors that influence its use. Complement Ther Nurs Midwifery 10: $37-45$

15. Kohlberg L (1991) The philosophy of moral development: Moral stages and the idea of justice: San Francisco: Harbor Row.

16. Megson DY (2013) Should I be an advocate? A good question for HCAs British journal of healthcare assistants 7: 502-507.

17. British Institute for Learning Disability (2017) Types of Advocacy 2013.

18. Becker PH (1986) Advocacy in nursing: Perils and possibilities. Holist Nurs Pract 1: 54-63.

19. Wiseman SJ (1990) Patient Advocacy. AORN J 51: 754-762.

20. Chafey K, Rhea M, Shannon A, Spencer S (1998) Characterizations of advocacy by practicing nurses. J Prof Nurs 14: 43-52.

21. Segesten K, Fagring A (1996) Patient advocacy-an essential part of quality nursing care. Int Nurs Rev 43: 142-144.

22. Josse-Eklund A, Wilde-Larsson B, Petzäll K, Sandin-Bojö A (2014) Individual and organizational factors influencing registered nurses' attitudes towards patient advocacy in Swedish community health care of elders. Scand J Caring Sci 28: 486-495.

23. Pluye $\mathrm{P}$, Hong QN (2014) Combining the power of stories and the power of numbers: mixed methods research and mixed studies reviews. Annu Rev Public Health 35: 29-45.

24. Liberati A, Altman D, Tetzlaff J, Mulrow C, Gøtzsche P, et al. (2009) The PRISMA statement for reporting systematic reviews and meta-analyses of studies that evaluate healthcare interventions: Explanation and elaboration. British medical Journal 339: b2700.

25. Critical Appraisal Skills Program (2013) Making sense of evidence. Oxford CASP UK.

26. Kolawole I (2017) Nurses' perception and patients' validation of nurses' advocacy roles in promotion of surgical patients' safety and rights in three hospitals, Ibadan, Nigeria. West African Journal of Nursing.

27. Vaartio H, Leino-Kilpi H, Salanterä S, Suominen T (2006) Nursing advocacy: How is it defined by patients and nurses, what does it involve and how is it experienced. Scand J Caring Sci 20: 282-292.

28. Sundqvist A, Anderzén-Carlsson A, Nilsson U, Holmefur M (2016) Protective nursing advocacy: Translation and psychometric evaluation of an instrument and a descriptive study of Swedish registered nurse anesthetists' beliefs and actions. J Perianesth Nurs 3: 58-68.

29. Bu X, Wu Y (2007) Development and psychometric evaluation of the instrument: Attitude toward patient advocacy. Res Nurs Health 31: 63-74.

30. Elewa A, Etway E, El Guindy H (2016) Nursing intern's perception regarding patients' rights and patients' advocacy. Journal of SOJ Nursing \& Health Care 2: 1-6.

31. El Seesy N, Al Nagshabandi E (2016) Nurses' attitudes toward patient advocacy in oncology department university hospital. American Journal of Nursing Science 5: 266-271.

32. Beigzadeh M, Borhani F, Ahmadi F, Abbaszadeh A (2016) Nurses attribution to the role of patient advocacy in intensive care units of hospitals of Tehran University of medical sciences. Journal of Bioscience Biotechnology Research Communities 9: 884-890.

33. Motamed-Jahromi M, Abbaszadeh A, Tatar K (2015) Iranian nurses perceptions of patient advocacy. Journal of Nursing and Midwife Sciences 2: $53-58$

34. Abbaszadeh A, Borhani F, Motamed-Jahromi M (2013) Nurses' attitudes towards nursing advocacy in the southeast part of Iran. Journal of Applied Environmental and Biological Sciences 3: 88-93.

35. Motamed-Jahromi M, Abbaszadeh A, Borhani F, Zaher H (2012) Iranian nurses' attitudes and perception towards patient advocacy. Journal of ISRN Nursing 2012: 1-5.

36. Tomaschewski-Barlem J, Lunardi V Barlem E, Ramos A Silveira R, et al. (2016) How have nurses practiced advocacy in the hospital context: A foucaultian perspective. Journal of Texto Contexto Enferm 25: 1-9.

37. Davoodvand S, Abbaszadeh A, Ahmadi F (2016) Patient advocacy from the clinical nurses' viewpoint: A qualitative study. J Med Ethics Hist Med 9: 1-9.
38. Breeding J, Turner D (2002) Registered nurses' lived experience of advocacy within a critical care unit: A phenomenological study. Aust Crit Care 15: 110-117.

39. O'Connor T, Kelly B (2005) Bridging the gap: A study of general nurses perceptions of patient advocacy in Ireland. Nurs Ethics cs 12: 453-467.

40. Mallik M (1997) Advocacy in nursing-perceptions of practicing nurses. J Clin Nurs 6: 303-313.

41. Sundqvist A, Carlsson A (2013) Holding the patient's life in my hands: Swedish registered nurse anaesthetists' perspective of advocacy. Scand Caring Sci 28: 281-288.

42. Negarandeh R, Oskouie F, Ahmadi F, Nikravesh M (2008) The meaning of patient advocacy for Iranian nurses. Nurs Ethics 15: 57-467.

43. Boyle $\mathrm{H}$ (2005) Patient advocacy in the perioperative setting. AORN J 82: 250-262.

44. Bull R, FitzGerald M (2004) Nurses' advocacy in an Australian. Journal of AORN 79: 1265-1274.

45. Toda Y, Sakamoto M, Tagara A, Takahashi M, Davis A, et al. (2015) Patient advocacy: Japanese psychiatric nurses recognizing necessity for intervention. Nurs Ethics 22: 765-777.

46. Blaževičienè A, Newland J, Čivinskienè V, Beckstrand R (2017) Oncology nurses' perceptions of obstacles and role at the end-of-life care: Cross sectional survey. BMC Palliat Care 16: 74

47. Gooselin-Acomb T, Schneider S, Clough R, Veenstra B (2007) Nursing advocacy in North Carolina. Oncol Nurs Forum 34: 1070-1074.

48. Kohnke MF (1982) Advocacy: Risk and reality. St. Louis: C V Mosby Company

49. Fowler MD (1989) Social advocacy. Heart \& Lung 18: 97-99.

50. McSteen K, McAlpine C (2006) The role of the nurse as advocate in ethically difficulty care situations with dying patients. Journal of Hospice and Palliative Nursing 8: 259-269. 